\title{
Palladium on Paper as a Low-cost and Flexible Material for Fast Hydrogen Sensing
}

\author{
Boyi Wang ${ }^{1}$ - Yasumasa Nara ${ }^{2}$. Takeshi Hashishin ${ }^{3}$. Dzung Viet \\ Dao $^{1}$. Yong $\mathbf{Z h u}^{1 *}$
}

Received: date / Accepted: date

\begin{abstract}
To improve the hydrogen detection performance, a flexible palladium-based hydrogen sensor was designed and fabricated on normal photocopy paper. The paper substrate offers advantages such as light weight, low cost, flexibility and unique surface texture. A conventional vacuum evaporation technique was utilized for $60 \mathrm{~nm}$ palladium deposition on the paper and glass substrates. The unique surface texture of the paper effectively increased the surface area to volume ratio for the sensing element, which achieved a higher gas response with faster speed than the glass-based sensor. In addition, we investigated the temperature impacts on sensing performance of the paper-based hydrogen sensor at room temperature and $50^{\circ} \mathrm{C}$. Furthermore, the flexibility test results of the paper-based hydrogen sensor showed that the sensing performances were impervious to mechanical bending of 5.7 degrees.
\end{abstract}

Keywords Flexible $\mathrm{H}_{2}$ sensor - Microfiber networks · Normal photocopy paper $\cdot$ Nano-shell network

\section{Introduction}

The inescapable exhaustion of fossil fuel reserves has led to a deep interest in alternative and renewable en-

*Yong Zhu

Queensland Micro- and Nanotechnology Centre, Griffith

University, Nathan, QLD 4111, Australia

E-mail: y.zhu@griffith.edu.au

${ }^{1}$ Queensland Micro- and Nanotechnology Centre, Griffith University, Nathan, QLD 4111, Australia

${ }^{2}$ Department of Materials Science and Engineering, Faculty of Engineering, Kumamoto University, Kumamoto, Japan

${ }^{3}$ Division of Materials Science and Chemistry, Faculty of Advanced Science and Technology, Kumamoto University, Kumamoto, Japan ergy resources [1]. Hydrogen $\left(\mathrm{H}_{2}\right)$, as a clean, affordable and environmentally friendly energy carrier, is a potential replacement for fossil fuels. Consequently, the problem of depleting fossil fuels can be addressed with $\mathrm{H}_{2}$ wide-ranging applications, such as $\mathrm{H}_{2}$ fuel cells [2], propulsion systems, and $\mathrm{H}_{2}$-fueled cars [3]. However, $\mathrm{H}_{2}$ is a highly flammable gas and detonates when its concentration is over $4 \%$ in air; and it is also colourless, odourless and tasteless. These properties of $\mathrm{H}_{2}$ make the safety of hydrogen applications to be a serious consideration. Therefore, a fast, inexpensive, and reliable detection device of $\mathrm{H}_{2}$ gas is required to avoid the hazard of $\mathrm{H}_{2}$-based applications [3].

Conventionally, the most economically available $\mathrm{H}_{2}$ detection devices are metal-oxide based, such as tungsten oxide sensors [4,5], and tin oxide sensors [6]. While they have an acceptable lifetime, they have poor $\mathrm{H}_{2}$ selectivity, and require a high operational temperature during the gas detection process. In the recent decade, palladium $(\mathrm{Pd})$ and its alloy [7-9] have been presented as a superior sensing material compared with metaloxide, which lead to high sensitivity and selectivity of $\mathrm{H}_{2}$ at room temperature. Although the detection performance of $\mathrm{Pd}$ alloy is better than pure $\mathrm{Pd}$, the fabrication process is complex and expensive [10-12]. In order to achieve a low-cost, fast-response, high-sensitivity $\mathrm{H}_{2}$ sensing, pure $\mathrm{Pd}$ is the practicable sensing material for $\mathrm{H}_{2}$ leakage detection and concentration measurement.

Although pure Pd has high sensitivity and selectivity to $\mathrm{H}_{2}$, the pure $\mathrm{Pd}$ thin film $\mathrm{H}_{2}$ sensor has two major problems: surface peeling off and slow response. These problems are significant matters for practical applications. To address these issues, the low-dimensional nanostructured Pd-based $\mathrm{H}_{2}$ sensor has been a promising research 
topic in the last few decades $[1,3,12,13]$. The nanosized $\mathrm{Pd}$ sensing element can inhibit its crystal defects, and improve the mechanical strength of the film. Therefore, the $\mathrm{Pd}$ thin film $\mathrm{H}_{2}$ sensor is able to avoid the peeling off phenomenon. In addition, the nanosized Pd-based $\mathrm{H}_{2}$ sensor also provides a faster response and higher resolution, owing to the high surface area to volume ratio $[14-16]$.

Recently, researchers have presented various $\mathrm{Pd}$ nanostructures for $\mathrm{H}_{2}$ gas detection devices $[1,3,13,17]$. Kim et al. [1] reported that a nanostructured $\mathrm{Pd}$-based $\mathrm{H}_{2}$ sensor using anodic aluminium oxides (AAOs). The AAOs template was applied to form nanoporous $\mathrm{Pd}$ film, which led to enhancing the surface area of the sensing layer and improving the performance of the $\mathrm{H}_{2}$ sensor. However, the sensor was not impressive in its sensitivity. A $\mathrm{Pd}$ wire network-based hydrogen sensor on glass was presented by Walia et al. [17]. The research indicated that the $\mathrm{Pd}$ wire network was implemented with the crackle lithography technique, which was able to fabricate the microsized crackles on the glass. Because this novel fabrication technique was utilized, the reaction interface of $\mathrm{Pd}$ and $\mathrm{H}_{2}$ molecules was increased, and thus achieved high sensitivity and fast response. Lim et al. [3] investigated a flexible $\mathrm{Pd}$-based $\mathrm{H}_{2}$ sensor with high sensitivity and short response time. The $\mathrm{Pd}$ nanowires were fabricated by using the nanoimprint lithography technique, and then the nanowires were transferred to a polycarbonate substrate. Overall, the aforesaid nanostructured $\mathrm{Pd}$-based $\mathrm{H}_{2}$ sensors were fabricated by using advanced fabrication techniques to achieve the large surface area to volume ratio of $\mathrm{Pd}$, however the processes were complex and/or costly $[13,18,19]$.

In the present work, a low-cost and flexible Pd-based $\mathrm{H}_{2}$ sensor is designed, fabricated and characterized. In order to enhance the $\mathrm{H}_{2}$ detection performance of the sensor, the surface texture of the normal photocopy paper (NPP) is effectively utilized to achieve low dimensional nanostructures in this investigation. The $60 \mathrm{~nm}$ Pd thin film is coated on the NPP by using the vacuum evaporation system, and the characterization of the microfiber networks sensing layer is analyzed by a scanning electron microscope (SEM). The combination of the 2-dimensional (2D) nanosized sensing layer and microfiber networks can form a nano-shell sensing structure, thereby significantly increasing the surface area to volume ratio. Thanks to the conventional fabrication process and the ubiquitous substrate, the sensor offers advantages such as simple fabrication, low cost, flexibility, light weight, and mass production. The presented $\mathrm{H}_{2}$ sensor is capable of detecting the low concen- tration of $100 \mathrm{ppm} \mathrm{H}_{2}$, and has a short response time of 12 seconds when exposed to $10,000 \mathrm{ppm}_{2}$ at room temperature. In addition, the temperature effect and bending effect of the sensor were investigated during the experimental testing process.

\section{Design and Experiment}

The process flow for the fabrication of the Pd microfiber networks $\mathrm{H}_{2}$ gas sensor is illustrated in Figure 1.The vacuum evaporation technique is utilized to deposit pure $\mathrm{Pd}$ thin film on the surface of the NPP (A4/80gsm, Paper Australian Pty Ltd.) substrate. Because of the surface texture of the NPP substrate, the $\mathrm{Pd}$ microfiber networks are formed on the NPP substrate. Thus, the large surface area to volume ratio of the sensing element is achieved according to the microfiber morphology of the NPP. Moreover, the NPP is a low-cost, flexible, light, and ubiquitous material for the substrate of the $\mathrm{H}_{2}$ sensor.
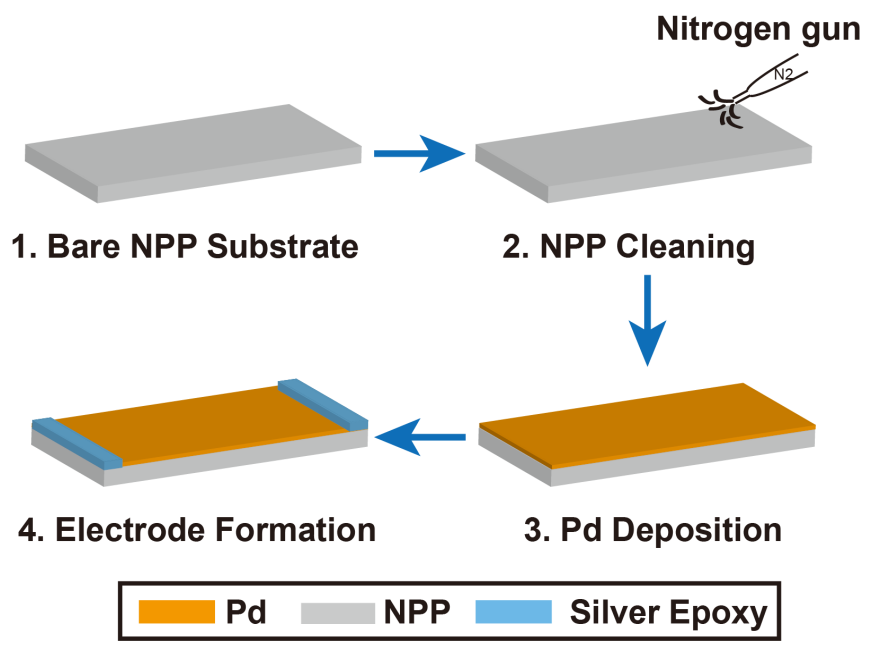

Fig. 1 Flow chart for fabrication of the Pd microfiber networks $\mathrm{H}_{2}$ gas sensor on normal photocopy paper (NPP).

The facile fabrication process flow of the $\mathrm{H}_{2}$ sensor is schematically described in Figure 1. First, dust on the surface of the NPP was removed by using a highpressure nitrogen gun. Then, $\mathrm{Pd}$ with a purity of $99.95 \%$ was deposited on the NPP surface by employing a vacuum evaporation system (VPC-260, ULVAC Technologies, Inc.) to form the microfiber networks structure with high density (superficial density) Pd layer. High film density is a critical parameter to improve the mechanical properties of the $\mathrm{Pd}$ film, and the adhesion to the substrate. To fabricate the superior mechanical property and smooth surface of the $\mathrm{Pd}$ thin film, the 
film deposition system was operated under a vacuum of $2.0 \times 10^{-5}$ Torr, and a current of 90 amperes. For sensing performance comparison and thickness reference purpose, a microscope cover glass slip was chosen to be placed adjacent to the NPP substrate. The glass was cut into the size of $20 \mathrm{~mm}$ by $5 \mathrm{~mm}$, cleaned in ethanol for 10 minutes in an ultrasonic bath, and then dried using a high pressure nitrogen gun. With the same evaporation conditions, $60 \mathrm{~nm} \mathrm{Pd}$ thin films on the NPP and glass substrates were achieved after 3 minutes of deposition time. The Pd thin film on NPP substrate was cut into pieces of $20 \mathrm{~mm}$ by $5 \mathrm{~mm}$ after the whole NPP substrate was transferred out of the vacuum evaporation system. Finally, the electrodes were made on the edges of sensors with silver epoxy.

The $\mathrm{H}_{2}$ sensor testing was implemented by placing the sensors in a sealed quartz tube (gas chamber) and connecting the sensors with measurement circuitry using soft gold wires, as illustrated in Figure 2. Pure nitrogen and $1 \% \mathrm{H}_{2}$ gas were connected to the mass flow controller (MFC), and the $\mathrm{H}_{2}$ concentration was controlled by the MFC. The gas flow rates of MFCs were controlled to obtain various $\mathrm{H}_{2}$ concentrations of 100 ppm, 2,000 ppm, 4,000 ppm, 6,000 ppm, 8,000 ppm and $10,000 \mathrm{ppm}$ for the sensor characterization.

Before the sensing experiments, pure nitrogen was fed into the chamber for 10 minutes to remove all the residual gases. During $\mathrm{H}_{2}$ concentration measurement, the mixed gas flow rate at the inlet of the gas chamber was set at 100 standard cubic centimetres per minutes (SCCM). Each concentration of $\mathrm{H}_{2}$ was flowed into the gas chamber for 300 seconds and was cut off for 300 seconds for recovery while nitrogen gas was flowing. To convert the resistance change of the sensor to voltage readings, a voltage divider was employed in the measurement setup. The applied DC voltage $(E)$ was $1 \mathrm{~V}$ and the standard resistor $(R)$ was set to be $2 \mathrm{k} \Omega$ and 220 $\Omega$ to match the resistances of NPP $(1.79 \mathrm{k} \Omega)$ and glass-

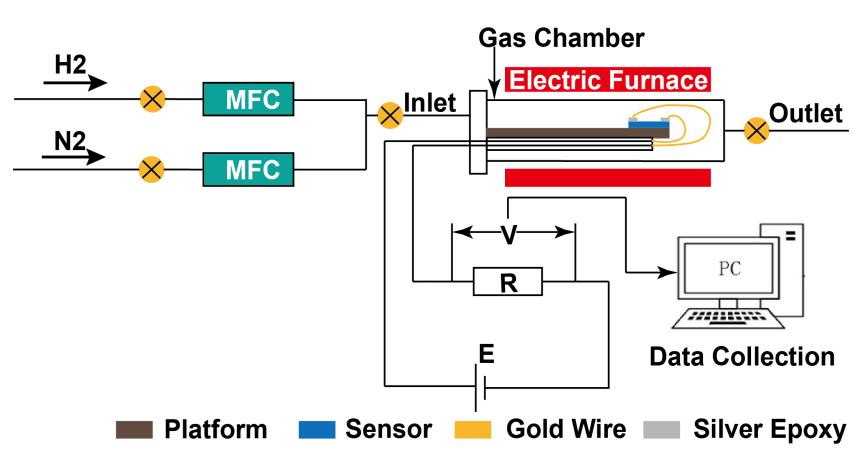

Fig. 2 Schematic diagram of the $\mathrm{H}_{2}$ sensor testing system. based $(207.85 \Omega$ ) sensors, respectively. In real-time, the voltage change of $R$ was recorded by a digital multimeter once per second and logged into a computer while the $\mathrm{H}_{2}$ sensor was exposed to different concentrations of $\mathrm{H}_{2}$. All the tests of the NPP-based hydrogen sensor were carried out under three different conditions, including room temperature, $50^{\circ} \mathrm{C}$, and bending at room temperature. The gas response $(G)$ of the $\mathrm{H}_{2}$ sensor was described as shown in Equation (1):

$G=\frac{R_{H}-R_{N}}{R_{N}} \times 100 \%=\frac{\Delta R}{R_{N}} \times 100 \%$

where $R_{N}$ and $R_{H}$ are the sensor resistance in nitrogen and after the mixed $\mathrm{H}_{2}$ gas injection, respectively. The range of the $\mathrm{H}_{2}$ concentration was from $100 \mathrm{ppm}$ to 10,000 ppm.

\section{Results and Discussion}

A scanning electron microscope (SEM) was used to image the surface morphology of the NPP-based $\mathrm{H}_{2}$ sensor. To avoid charging effects during SEM imaging, it was necessary to connect the surface of the $\mathrm{Pd}$ thin film to the testing platform with double-sided carbon tape. The surface morphology images of the NPP-based $\mathrm{H}_{2}$ sensor are presented in Figure 3 with two different magnification. The network structure of multilayer microfiber is clearly shown in Figure 3(a); and up to approximate $30 \mu \mathrm{m}$ in diameter of the $\mathrm{Pd}$ microfiber can be observed in Figure 3(b). The combination of the nanosized sensing layer and microfiber networks can improve the surface area to volume ratio owing to the transformation from 2D to nano-shell networks structure. The detailed analysis will be discussed later in this section. Additionally, the surface elements of the sensor were plotted according to the energy dispersive X-ray analysis, as shown in Figure 4, which demonstrated that carbon, oxygen, palladium, and calcium were obviously contained on the surface of the NPP-based $\mathrm{H}_{2}$ sensor.

The response time, recovery time and gas response of the $\mathrm{Pd}$-based $\mathrm{H}_{2}$ sensor when exposed to various $\mathrm{H}_{2}$ gas concentrations are illustrated in Figure 5. The response time is defined as the time needed to change the resistance of the sensor from the initial value to $90 \%$ of the final stable value, whereas the recovery time is defined as the time needed to change the resistance from the stable value to $10 \%$ of it.

As well known, $4 \% \mathrm{H}_{2}$ concentration is a critical value for $\mathrm{H}_{2}$ gas to be explosive. Due to the safety consideration, the maximum $\mathrm{H}_{2}$ concentration was set at well 


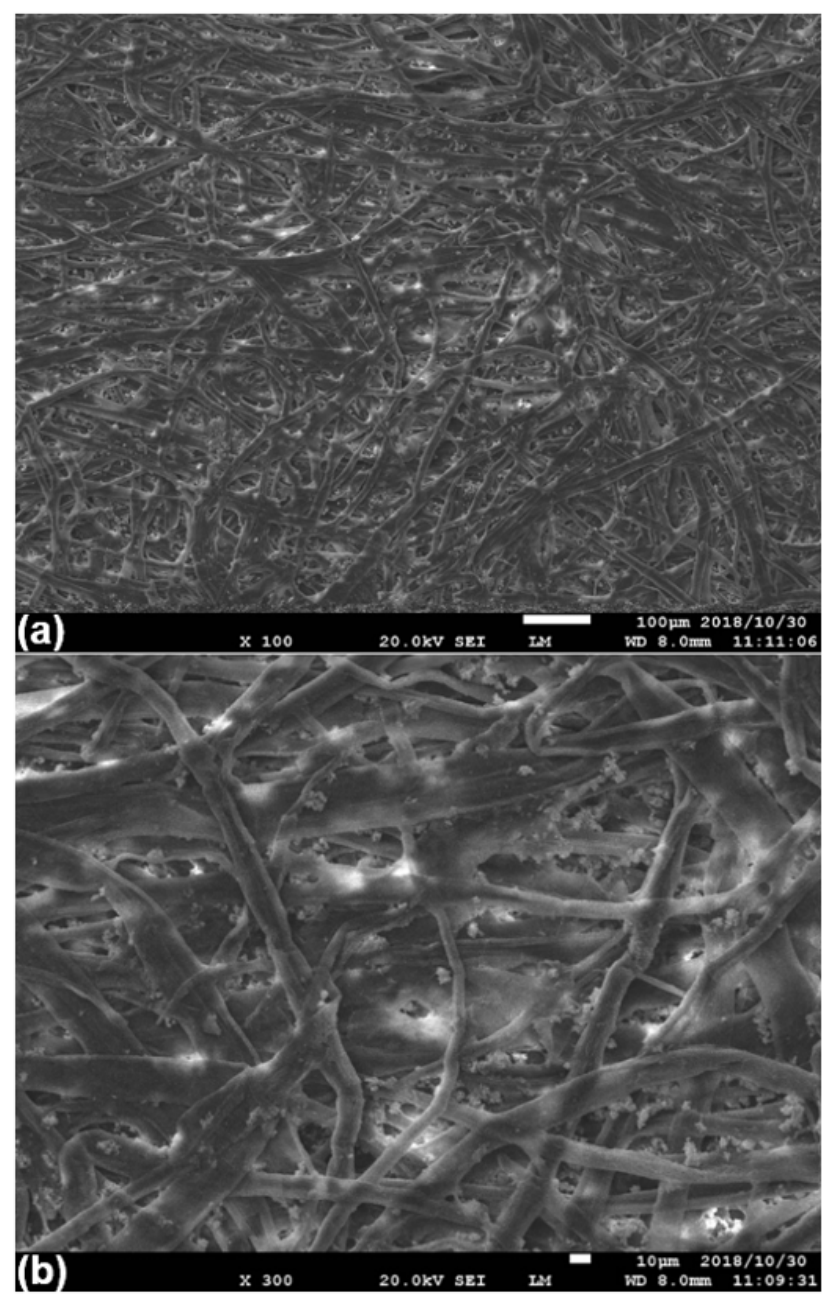

Fig. 3 Scanning electron microscopy (SEM) images of $60 \mathrm{~nm}$ Pd microfiber networks coated on the NPP. Zoom in (a) 300 times; (b) 900 times.

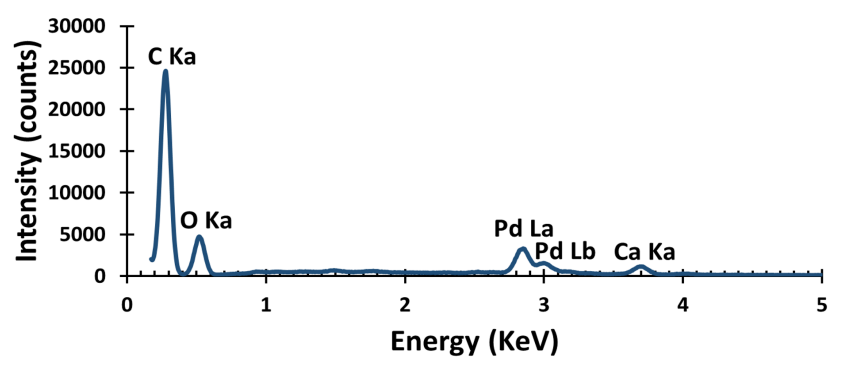

Fig. 4 Surface elemental analysis of the sensing area.

below $4 \%$ all the time. Figure 5(a) represents the response times of the $\mathrm{H}_{2}$ sensor with the glass and NPP substrates when exposed to specific concentrations from $100 \mathrm{ppm}$ to $10,000 \mathrm{ppm}$. For instance, the resistance of the glass-based $\mathrm{H}_{2}$ sensor rose quickly when exposed to $10,000 \mathrm{ppm} \mathrm{H}_{2}$, and its resistance reached $90 \%$ of the final stable value within 47 seconds. The large surface area to volume ratio of the $\mathrm{H}_{2}$ sensor was attained because the nanosized $\mathrm{Pd}$ thin film was coated on a flat glass substrate. Therefore, the glass-based $\mathrm{H}_{2}$ sensor was able to provide the fast response speed. On the other hand, as shown in Figure 5(a), NPP-based $\mathrm{H}_{2}$ sensor achieved much shorter response time of 12 seconds at $10,000 \mathrm{ppm}_{2}$. The surface morphology of the NPP is an effective means to further improve the surface area to volume ratio of the $\mathrm{Pd}$ thin film, as shown in Figure 6.

The principles of absorption and desorption are same for glass-based and NPP-based $\mathrm{H}_{2}$ sensors. In terms of the distinctive interaction between $\mathrm{Pd}$ and $\mathrm{H}_{2}$ gas, the $\mathrm{H}_{2}$ partial pressure changes along with the absorption and desorption processes of the Pd-based $\mathrm{H}_{2}$ sensor when exposed to $\mathrm{H}_{2}$ gas [20]. During the absorption process, the $\mathrm{H}_{2}$ partial pressure of the outside of the $\mathrm{Pd}$ thin film is higher than the inside of the sensing element, leading to hydrogen atoms diffusion into the $\mathrm{Pd}$ thin film. Based on this phenomenon, the $\mathrm{Pd}-\mathrm{H}$ hydride is formed and results in the $\mathrm{Pd}$ physical properties changes, involving mass, volume and electrical resistance. When the $\mathrm{Pd}$-based $\mathrm{H}_{2}$ sensor is exposed to air or nitrogen, the $\mathrm{H}_{2}$ partial pressure in the $\mathrm{Pd}$ thin film is higher than that on the surface, which causes the desorption occurrence [21].

As presented in Figure 6, the NPP-based $\mathrm{H}_{2}$ sensor is capable of achieving higher detection performance compared with the glass-based sensor, and the reason can be explained by the following equations. The surface area to volume ratio of the $\mathrm{Pd}$ thin film on the glass substrate is inversely proportional to its thickness, as shown in Equation (2).

$(A / V)_{\text {Glass }}=\frac{A}{A \times H_{P d}}=\frac{1}{H_{P d}}$

where $(A / V)_{\text {Glass }}$ is the surface area $(A)$ to volume $(V)$ ratio, and $H_{P d}$ is the thickness of the $\mathrm{Pd}$ film on the glass substrate.

During the Pd deposition process, the flat Pd thin film with the average thickness of $H_{P d}$ was coated on the glass substrate, as shown in Figure 6(a). However, the thickness of the Pd thin film on NPPs microfiber was not uniform during the same deposition conditions: the $\mathrm{Pd}$ film on the side wall of the fiber was thinner than that on the top and bottom, as presented in Figure 6(b). In that case, we presumed the thickness of the Pd film on the top and bottom of the fiber was $H_{P d}$, the side part was $H_{S}$. Thus, the surface area to volume ratio of the Pd thin film on NPP substrate, $(A / V)_{N P P}$, can be defined as Equation (3) 


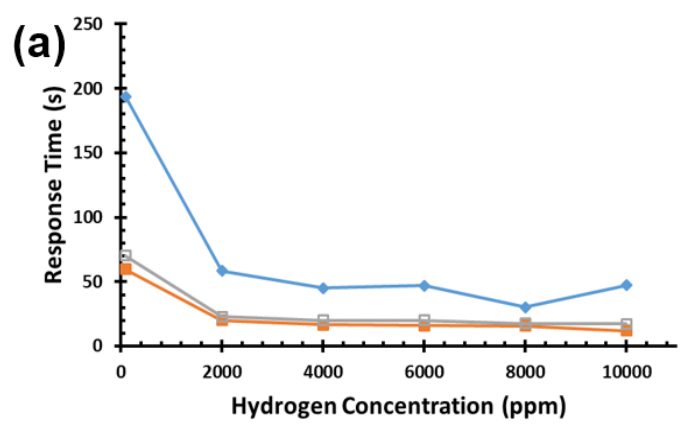

(c)

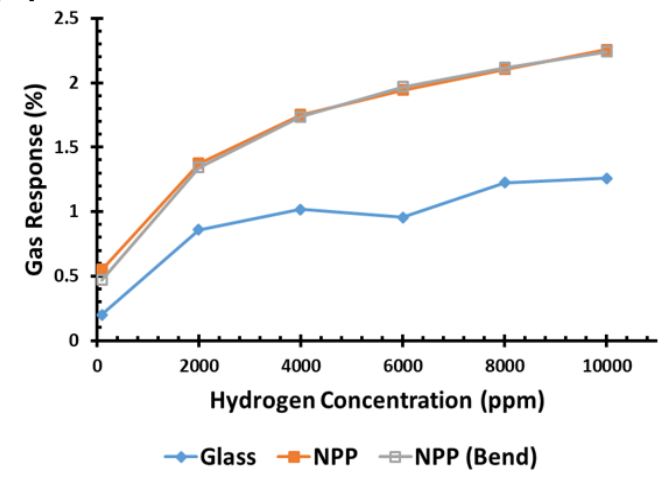

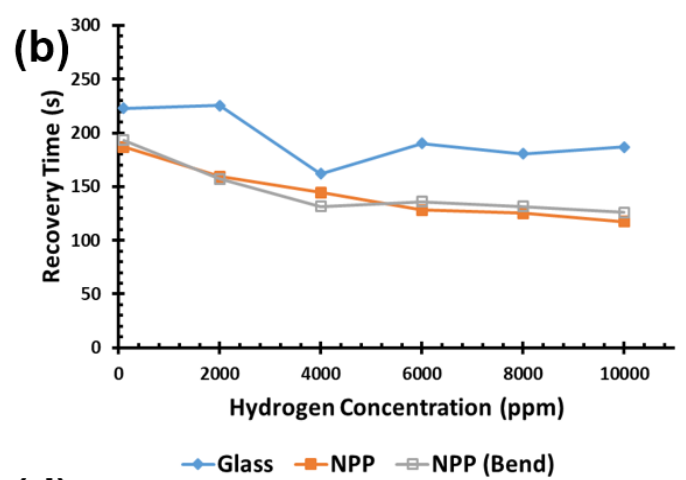

(d)

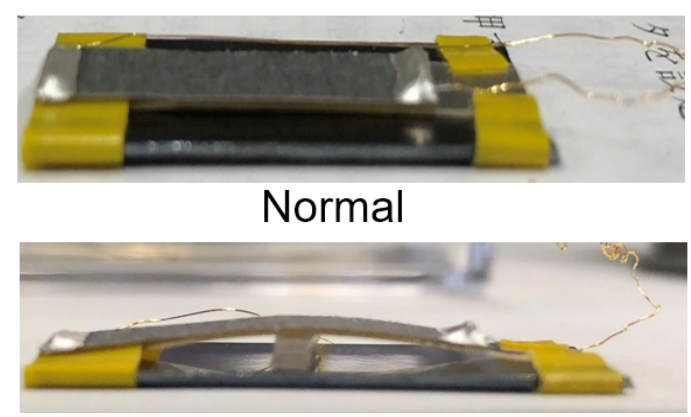

Bending

Fig. 5 Performance of the $\mathrm{H}_{2}$ sensor. (a) Response time, (b) recovery time, and (c) gas response for the sensor on a glass substrate, NPP substrate, and bending condition, at $\mathrm{H}_{2}$ concentration from $100 \mathrm{ppm}$ to 10,000 ppm. (d) The photographs of NPP-based $\mathrm{H}_{2}$ sensor under normal and bending conditions.

(a)

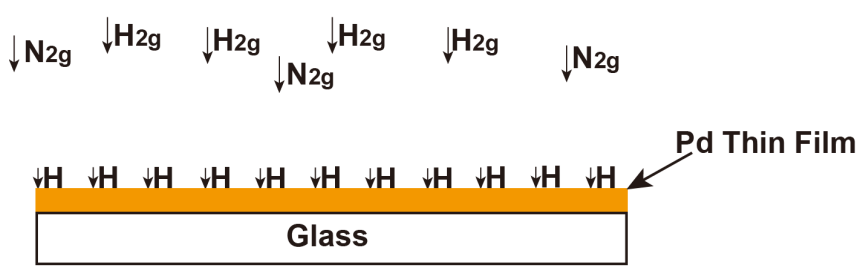

(b)

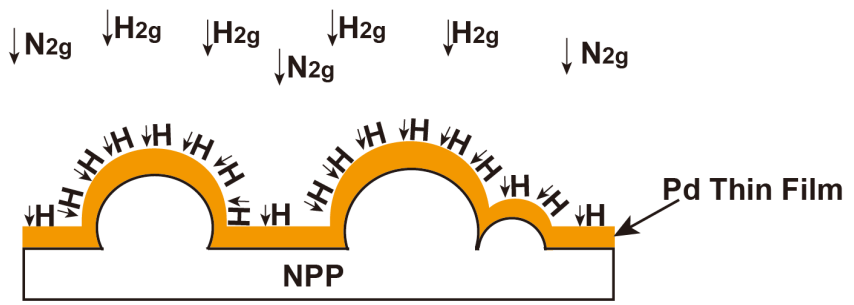

Fig. 6 Cross-sectional view of surface morphology for the glass and NPP substrate. (a) and (b) are the sensing mechanisms of the glass-based and NPP-based $\mathrm{H}_{2}$ sensors, respectively.

$(A / V)_{N P P}=\frac{A_{T B}+A_{S}}{A_{T B} H_{P d}+A_{S} H_{S}}$

where $A_{T B}$ is the total surface area of the top and bottom parts; and $A_{S}$ is the total area of side wall. $H_{S}$ is the film thickness of the side wall. Because $\left(H_{S^{-}} H_{P d}\right)$ is less than zero, thus Equation (3) can be simplified as presented as Equation (4).

$(A / V)_{N P P}=\frac{1}{H_{P d}+\frac{A_{S}}{A_{T B}+A_{S}}\left(H_{S}-H_{P d}\right)}>\frac{1}{H_{P d}}$

Combination of Equations (2) and (4) indicates that the NPP-based $\mathrm{H}_{2}$ sensor has a larger surface area to volume ratio than glass-based. Thus, the nano-shell network structure of $\mathrm{Pd}$ microfibers with larger surface area to volume ratio was formed after $\mathrm{Pd}$ coated the surface of the NPP, which led to increasing the reaction interface of the $\mathrm{Pd}$ and $\mathrm{H}_{2}$ molecules. Therefore more diffusion pathways of atomic hydrogen were provided on the surface of $\mathrm{Pd}$ thin film. As a result, the gas response speed can be improved.

The recovery times of the NPP-based and glass-based $\mathrm{H}_{2}$ sensors are presented in Figure 5(b), the recovery speed of both $\mathrm{H}_{2}$ sensors are also affected by the types of the substrates. The hydrogen atoms in NPP-based $\mathrm{H}_{2}$ sensor were fully released to the chamber within 117 seconds for $10,000 \mathrm{ppm}_{2}$, which was about 60 seconds faster than the glass-based sensor. In addition, the larger surface area to volume ratio of the $\mathrm{Pd}$ thin 
(a)

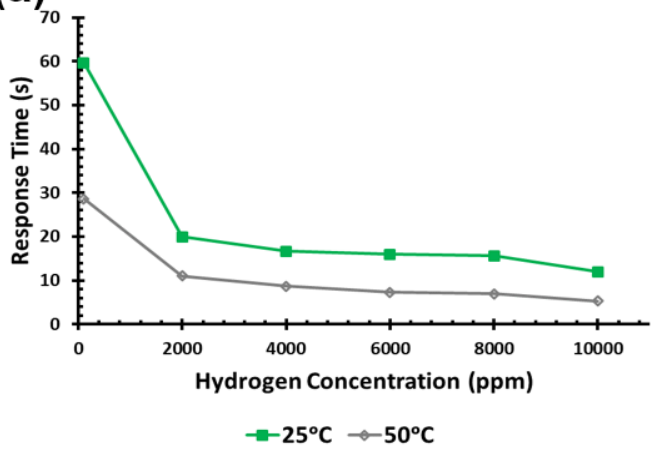

(c)

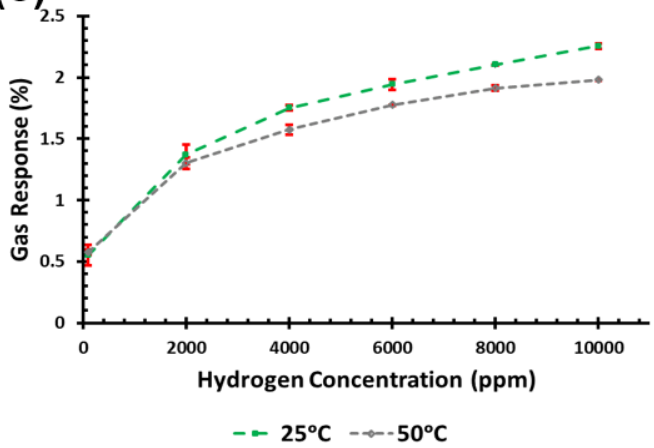

(b)

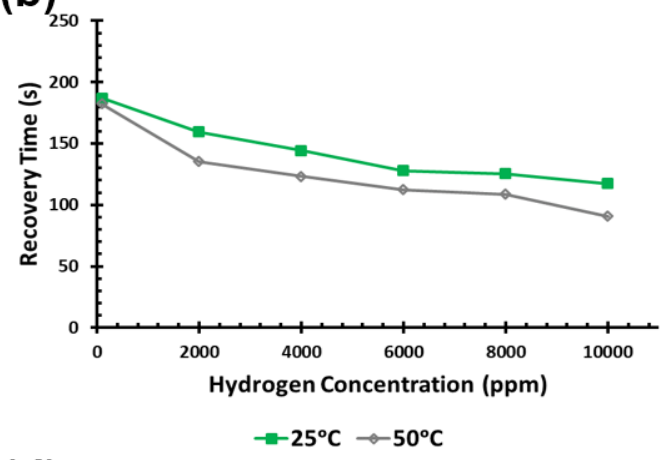

(d)

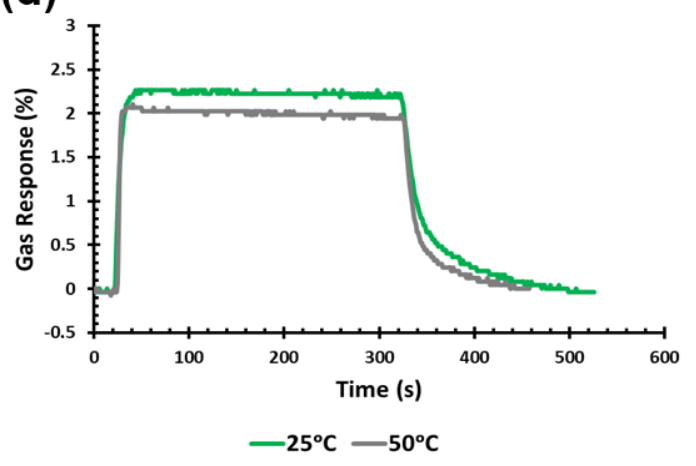

Fig. 7 Gas sensing performances of the NPP-based $\mathrm{H}_{2}$ sensor at $25^{\circ} \mathrm{C}$ and $50^{\circ} \mathrm{C}$. (a) response time, (b) recovery time, (c) gas response with standard deviation, $\mathrm{N}=3$, and $(\mathrm{d})$ the gas response curve for the $\mathrm{NPP}$-based hydrogen sensor at a $\mathrm{H}_{2}$ concentration of 10,000 ppm.

film can have smaller transverse dimensions, therefore the more hydrogen atoms can be absorbed in the interstitial sites of the Pd lattice [22]. Thus, more electron scattering in $\mathrm{Pd}$ decreases the mobility of electrons, and the resistance of the $\mathrm{Pd}$-based $\mathrm{H}_{2}$ sensor is increased. This indicates that the larger surface area to volume ratio of the $\mathrm{Pd}$-based $\mathrm{H}_{2}$ sensor has a higher gas response, as proved in Figure $5(\mathrm{c})$. At $\mathrm{H}_{2}$ concentrations of $100,2,000,4,000,6,000,8,000$ and $10,000 \mathrm{ppm}$, the gas responses of the NPP-based $\mathrm{H}_{2}$ sensor were 0.55 , $1.37,1.75,1.94,2.10$ and $2.25 \%$, respectively. By comparison, the gas response of the sensor based on the glass substrate was $1.25 \%$ for $10,000 \mathrm{ppm} \mathrm{H}_{2}$, which was $44.4 \%$ lower than that of the NPP-based $\mathrm{H}_{2}$ sensor at the same $\mathrm{H}_{2}$ concentration. This validated that the NPP based sensor has a higher surface area to volume ratio as discussed in this section.

Apart from the microfiber texture, the NPP substrate has many other advantages over the glass substrate, for example its flexible property. To investigate the flexibility performance of the NPP-based $\mathrm{H}_{2}$ sensor, the bending test was implemented, as shown in Figure 5(d). For comparison purpose, the bending test of the $\mathrm{H}_{2}$ sensor was based on the same NPP-based hydrogen sensor. The NPP based sensor was bended by 5.7 degrees
(1 $\mathrm{mm}$ above the platform) as shown in Figure 5(d). The response time, recovery time and gas response of the bended NPP-based $\mathrm{H}_{2}$ sensor with the $\mathrm{H}_{2}$ concentrations from 100 to 10,000 ppm are included in Figure 5(a), (b) and (c), respectively. Evidently, there were not obvious discrepancies in the response time, recovery time, and gas response before and after the NPP-based $\mathrm{H}_{2}$ sensor was bended. Therefore, it implies that the NPP-based $\mathrm{H}_{2}$ sensor is suitable for flexible sensing applications without performance degradation.

The working temperature of sensors has been confirmed to be a significant factor effecting sensor performances. As shown in Figure 7, the response time, recovery time, and gas response of the NPP-based $\mathrm{H}_{2}$ sensor were plotted during exposure to $100-10,000$ ppm hydrogen at room and high temperature $\left(25^{\circ} \mathrm{C}\right.$ and $\left.50^{\circ} \mathrm{C}\right)$. Theoretically, the movement of gas atoms increases with the increase of temperature, especially for hydrogen with small molecular mass [10]. Thus, the absorption and desorption rates increase at higher temperatures, resulting in shorter response time and recovery time, as proved in Figure 7(a) and (b). However, lower gas response was obtained when temperature was increased from room temperature to $50^{\circ} \mathrm{C}$, as presented in Figure $7(\mathrm{c})$. In addition, the standard deviations of the gas 
responses for the NPP-based $\mathrm{H}_{2}$ sensor at room temperature and $50^{\circ} \mathrm{C}$ were less than $\pm 0.05 \%$ and $\pm 0.03 \%$, respectively. Therefore, the high repeatability and stability of the sensor were proved at both detection temperatures. To investigate the gas response details at same $\mathrm{H}_{2}$ concentration and different temperatures, the gas response curves were redrawn with the same starting time, as plotted in Figure $7(\mathrm{~d})$. The gas response of the NPP-based $\mathrm{H}_{2}$ sensor has decreased from $2.25 \%$ to $1.98 \%$. The unique relationship can be explained by Sieverts' Law, which states that the logarithm of $\mathrm{H}_{2}$ solubility increases linearly with the decreased temperature under the specified $\mathrm{H}_{2}$ partial pressure $[1,7,8]$.

The detailed relationship between the gas response and $\mathrm{H}_{2}$ concentration can be also clarified by Sieverts' Law in Equation (5)

$\left(\frac{H}{P d}\right)=K_{H} \times P_{H_{2}}^{1 / 2}$

where $(H / P d)$ is the concentration of the $\mathrm{H}_{2}$ dissolved in the $\mathrm{Pd}$ thin film (equilibrium condition), $K_{H}$ is the Sieverts' constant, and $P_{\left(H_{2}\right)}$ is the $\mathrm{H}_{2}$ partial pressure on the Pd thin film.

As depicted in Equation (5), the ratio of the dissolved hydrogen to palladium atoms is dependent on the square root of the $\mathrm{H}_{2}$ partial pressure $\left(\mathrm{H}_{2}\right.$ concentration in this experiment). The change of this ratio leads to a proportional gas response $(G)$, as reported in $[13,20]$. Using the experimental data in Figure $7(\mathrm{c})$, the $\mathrm{H}_{2}$ partial pressure (From $\mathrm{H}_{2}$ concentrations $>100 \mathrm{ppm}$ ) versus the gas response relationships at different temperatures are plotted in linear curves, as shown in Figure 8. Specifically, the calculated value of $K_{H}$ is reduced from 0.1566 to 0.1255 when temperature is increased from $25^{\circ} \mathrm{C}$ to $50^{\circ} \mathrm{C}$. According to Sieverts' Law, the lower

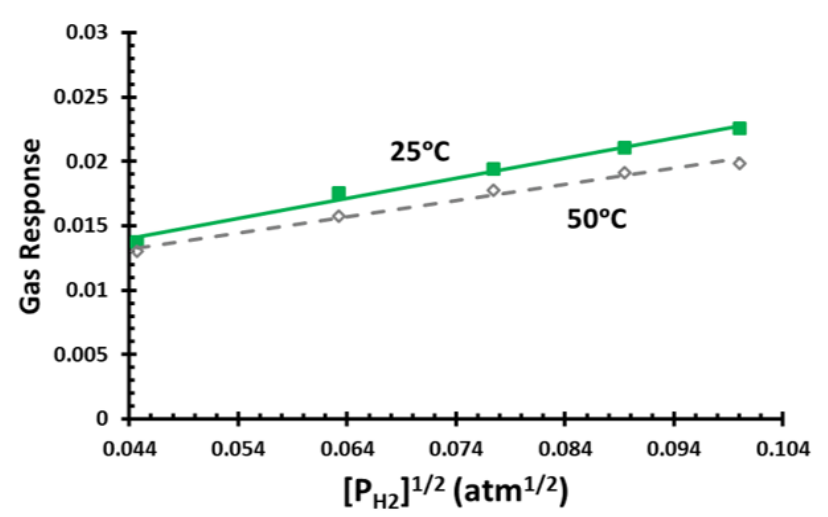

Fig. 8 The gas response of the NPP-based $\mathrm{H}_{2}$ sensor versus square root of $\mathrm{H}_{2}$ partial pressure at different temperatures. value of $K_{H}$ can reduce the gas response at the same concentrations. Therefore, as shown in Figure 7(c), the gas response is reduced when temperature increases.

\section{Conclusions}

This paper presents the superior gas sensing performance of a $\mathrm{Pd}$ microfiber networks $\mathrm{H}_{2}$ sensor which was fabricated using a simple vacuum evaporation technique. The networks of the $60 \mathrm{~nm} \mathrm{Pd}$ microfibers were formed on a NPP substrate, which was capable of improving the surface area to volume ratio of the $\mathrm{Pd}$ thin film. The experimental results indicated that the performance of the NPP-based $\mathrm{H}_{2}$ sensor was better than the glass-based sensor during the same detection conditions. This sensor presented a fast response of $12 \mathrm{sec}-$ onds and high gas response of $2.25 \%$ at $10,000 \mathrm{ppm}_{2}$. Comparatively, our sensor has a higher gas response than Wang's work [10], and more rapid response compared with Walia [17] and Lee [20]. The response time and recovery time was reduced at the high temperature, but the gas response was decreased. On the other hand, Its detection performances were unaffected by mechanical bending. Therefore, the NPP-based $\mathrm{H}_{2}$ sensor is flexible and suitable for room temperature $\mathrm{H}_{2}$ leakage detection. In addition, the advantages of the present sensor include simple fabrication, low cost, flexibility, light weight, and mass production.

\section{Acknowledgments}

The authors would like to thank professor Hiroshi Kubota, faculty of engineering, Kumamoto University, Japan for providing mico-fabrication and characterization facilities, and the technical support from Mr. Abe.

\section{Conflict of interest}

The authors declare that they have no conflict of interest.

\section{References}

1. B.J. Kim, J.S. Kim, Int. J. Hydrogen Energy 39, 1650016505 (2014)

2. H. Görgün, M. Arcak, S. Varigonda, SA. Bortoff, Int. J. Hydrogen Energy 30, 447-457 (2005)

3. S.H. Lim, B. Radha, J.Y. Chan, M.S.M. Saifullah, G.U. Kulkarni, G.W. Ho, ACS Appl. Mater. Interfaces 5, 72747281 (2013)

4. J. Tamaki, T. Hashishin, Y. Uno, D.V. Dao, S. Sugiyama, Sensors Actuators B 132, 234-238 (2008) 
5. D.V. Dao, K. Shibuya, T.T. Bui, S. Sugiyama, Proced. Eng. 25, 1149-1152 (2011)

6. B. Wang, L.F. Zhu, Y.H. Yang, N.S. Xu, G.W. Yang, J. Phys. Chem. C 112, 66436647 (2008)

7. J.H. Yoom, B.J. Kim, J.S. Kim, Mater. Chem. Phys. 133, 987-991 (2012)

8. H. Song, Y.P. Chen, G. Zhang, Y. Liu, P.C. Huang, H.W. Zhao, M.H. Yang, J.X. Dai, Z. Li, Sensors Actuators B 216, 11-16 (2015)

9. H. Song, Z.J. Luo, M.Y. Liu, G. Zhang, W. Peng, B. Wang, Y. Zhu, Sensors 18, 1448 (2018)

10. M. Wang, Y, Feng, Sensors Actuators B 123, 101-106 (2007)

11. N. Tasaltin, S. Öztürk, N. Kilinc, Z.Z. Öztürk, Journal of Alloys and Compounds 509, 4701-4706 (2011)

12. B. Wang, Y. Zhu, Y.P. Chen, H. Song, P.C. Huang, D.V. Dao, Mater. Chem. Phys. 194, 231-235 (2017)

13. X.Q. Zeng, Y. L. Wang, H. Deng, M. L. Latimer, Z. L. Xiao, J. Pearson, T. Xu, H. H. Wang, U. Welp, G. W. Crabtree, W. K. Kwok, ACS Nano 5, 7443-7452 (2011)

14. P. Offermans, H.D. Tong, C.J.M. van Rijn, P. Merken, S.H. Brongersma, M. Crego-Calama, Appl. Phys. Lett. 94, 223110 (2009)

15. Y. Lim, Y. Lee, J. Heo, H. Shin, Sensors Actuators B 210, 218-224 (2015)

16. B. Wang, Y. Zhu, V. Huynh, M.A. Rahman, B. Hawkett, S. Sriram, D.V. Dao. (2019) https://doi.org/10.1007/9783-030-04290-5_12

17. S. Walia, R. Gupta, K. D. Rao, G. U. Kulkarni, ACS Appl. Mater. Interfaces 8, 23419-23424 (2016)

18. F. Yang, S.C. Kung, M. Cheng, J.C. Hemminger, R.M. Penner, ACS Nano. 4, 5233-5244 (2010)

19. K.J. Jeon, J.M. Lee, E. Lee, W. Lee, Nanotechnology 20, $135502(2009)$

20. E. Lee, J.M. Lee, J.H. Koo, W. Lee, T. Lee, Int. J. Hydrogen Energy 35, 6984-6991 (2010)

21. B. Wang, M.A. Rahman, Y. Nara, T. Hashishin, D.V. Dao, Y. Zhu, J. of Physics and Chemistry of Solids 131, 50-54 (2019)

22. X.Q Zeng, M.L. Latimer, Z.L. Xiao, S. Panuganti, U. Welp, W.K. Kwok, T. Xu, Nano Letters 11, 262-268 (2011) 